\title{
AISLAMIENTO Y CARACTERIZACIÓN DE UNA MIOTOXINA DEL VENE- NO DE LA SERPIENTE Bothrops brazili HOGE, 1953 (OPHIDIA: VIPERIDAE)
}

\author{
ISOLATION AND CHARACTERIZATION OF A MYOTOXIN FROM Bothrops \\ brazili HOGE, 1953 SNAKE VENOM (OPHIDIA: VIPERIDAE) \\ Carmen Pantigoso ${ }^{1}$, Enrique Escobar ${ }^{2}$ y Armando Yarlequé
}

\section{RESUMEN}

Se ha purificado una miotoxina del veneno de la serpiente Bothrops brazili, empleando un solo paso cromatográfico de intercambio iónico sobre CM-Sephadex C-50 con buffer acetato de amonio 0,05 M pH 7. La pureza de la proteina fue evaluada por PAGE con y sin SDS, inmunodifusión a inmunoelectroforesis. La proteina es de naturaleza básica y contiene $15,6 \%$ de Lys+Arg; además, no está glicosilada, carece de actividad enzimática, y por el método de Lowry se ha calculado que ella constituye el $25 \%$ de la proteina total del veneno.

Por PAGE-SDS y cromatografia de filtración, se ha determinado que la miotoxina tiene un peso molecular de $30 \mathrm{KDa}$, y está formada por 2 cadenas polipeptidicas de $15 \mathrm{KDa}$ cada una.

La inoculación de la miotoxina en el músculo gastrocnemius de ratones albinos, produce una severa necrosis del tejido.

La miotoxina no tiene actividad hemolitica ni anticoagulante; sin embargo, si produce edema, se ha calculado una DEM de $32.6 \mu \mathrm{g}$ de proteina.

Palabras clave: miotoxina, Bothrops brazili, veneno de serpiente, mionecrosis

\section{ABSTRACT}

A myotoxin from the venom of the snake Bothrops brazili has been purfifed by ion-exchange chromatography on $\mathrm{CM}$-Sephadex $\mathrm{C}-50$ with $0.05 \mathrm{M}$ ammonium acetate buffer $\mathrm{pH} 7$. The homogeneity was evaluated by PAGE with and without SDS, immunodiffusion and immunoelectrophoresis. The myotoxin is a basic protein with $15,6 \%$ of Lys +Arg; it is not a glicoprotein, has not enzymatic activity, and corresponds to $25 \%$ of the whole venom protein.

The molecular weight of the myotoxin was determined by PAGE-SDS and ge! filtration chromatograpiny. The myotoxin has $30 \mathrm{KDa}$ of molecular weight and two polypeptide chains of $15 \mathrm{KDa}$ each.

Myotoxin produces a severe necrosis on the gastrocnemius muscle of white mice.

The myotoxin does not have hemolytic nor anticoagulant activity. However, produces edema with a DEM of $32,6 \mu \mathrm{g}$ of protein.

Keywords: myotoxin, Bothrops brazill, snake venom, myonecrosis

\section{INTRODUCCIÓN}

La mayoria de serpientes venenosas del Perú pertenecen al género Bothrops (Familia Viperidae), y ellas son responsables de la ma-

'Lab de Biologla Molecular. Facultad de Ciencias Biológicas. UNMSM.

${ }^{2}$ Lab. de Bioquimica y Genélica Molecular. Facultad de Ciencias Biológicas. UNMSM. d190014@unmsm.eđu.pe yoría de accidentes ofidicos en nuestro país. Sus venenos se caracterizan por producir severo daño local incluyendo hemorragia y necrosis, y pueden ocasionar la muerte de la persona afectada, si ésta no es tratada adecuadamente.

Los venenos de estas serpientes contienen, principalmente, una gran variedad de protei- 
nas con actividad enzimática entre las que destacan una diversidad de enzimas proteoliticas, capaces de alterar la coagulación sanguinea y producir hemorragia. Igualmente las fosfolipasas son enzimas ampliamente distribuidas en estos venenos y ellas son responsables de la hidrólisis de fosfolípidos y de varios efectos biológicos como hemólisis, cardiotoxicidad, inhibición de la agregación de plaquetas, edema, etc. (Kini y Iwanaga, 1986a y 1986b).

En particular, la necrosis del tejido muscular (mionecrosis) es un efecto caracteristico del envenenamiento botrópico, que puede conducir a la disfunción o amputación de la zona afectada. En este proceso participan proteínas básicas denominadas miotoxinas, las cuales constituyen una familia de proteinas, estructural y antigénicamente relacionadas a las fosfolipasas. En este sentido, las miotoxinas botrópicas pueden ser de dos tipos: unas con actividad de fosfolipasa y otras sin actividad enzimática (Gutiérrez y Lomonte, 1997).

La serpiente Bothrops brazili "jergón shushupe" (Familia Viperidae, Subfamilia Crotalinae) es una especie cuya distribución geográfica abarca los departamentos de Amazonas, Loreto, Madre de Dios y Ucayali (Carrillo e Icochea, 1995). Su longitud aproximada es de 1,8 metros y presenta un color pardo con dibujos triangulares más oscuros sobre el dorso. Su alimento principal son pequeños roedores y lagartijas (Carrillo, 1983).

Cabe mencionar que las proteínas estudiadas de venenos de serpientes del Perú se han tratado exclusivamente de proteínas con actividad enzimática (Yarlequé et al., 1989; Pantigoso et al., 1996). En particular algunas de las proteinas que se han aislado y caracterizado en el veneno de $B$. brazili, son las enzimas similar a trombina (Limán, 1996), fosfolipasa (Zeballos et al., 1999) y proteolítica (Azañero et al., 2000).
En este trabajo se describe el aislamiento y caracterización de una proteina no enzimática con actividad miotóxica, lo que constituye el primer reporte de este tipo en nuestro medio.

\section{MATERIAL. Y MÉTODOS}

1 Veneno. Se utilizó veneno de Bothrops brazili, de especimenes procedentes de la región del Alto Marañón, mantenidos en cautiverio en el Serpentario "Oswaldo Meneses" del Museo de Historia Natural de la Universidad Nacional Mayor de San Marcos. El veneno extraído por presión manual de las glándulas venenosas fue liofilizado y conservado a $-8{ }^{\circ} \mathrm{C}$.

2 Purificación de la miotoxina. $100 \mathrm{mg}$ de veneno liofilizado de $B$. brazili fueron disueltos en $2 \mathrm{ml}$ de buffer acetato de amonio $0,05 \mathrm{M}, \mathrm{pH} 7,0$ y los restos insolubles se eliminaron por centrifugación a $4000 \mathrm{rpm}$ durante 20 minutos. Se tomó $1,95 \mathrm{ml}$ del sobrenadante y se aplicó a una columna de intercambio catiónico de CM-Sephadex C-50 (17 X 1,1 cm), utilizando como buffer de elución acetato de amonio 0,05 M pH 7,0. Las proteinas retenidas en la columna fueron eluidas agregando al buffer de corrida $\mathrm{NaCl}$ $0,3 \mathrm{M}$ y $0,6 \mathrm{M}$. La corrida se realizó a temperatura ambiente, a un flujo de $8 \mathrm{ml} / \mathrm{h}$ y la proteina fue estimada por absorción de luz ultravioleta a $280 \mathrm{~nm}$. El pico obtenido con

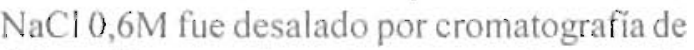
filtración empleando una columna de Sephadex G-25 (22 X 2,5 cm), luego de lo cual se evaluó la actividad miotóxica.

3 Cuantificación de proteína. El contenido proteico del veneno crudo y de la proteina purificada se determinó por el método de Lowry (195I). Para ello, $20 \mu l$ de la muestra se completaron con agua destilada hasta 0,5 $\mathrm{ml}$ y luego se agregó $2 \mathrm{ml}$ de solución alcalina (carbonato de sodio al $4 \%$, sulfato de cobre al $2 \%$ y tartrato de sodio y potasio al $4 \%$ 100:1:1), y se incubó a $37^{\circ} \mathrm{C}$ durante $15 \mathrm{mi}$ nutos. Después de este tiempo se agregó 0,5 
$\mathrm{ml}$ de RFC 1:6 y luego de 30 minutos de reposo a temperatura ambiente, se midió la absorbancia a $660 \mathrm{~nm}$. Como proteína estándar se utilizó albúmina bovina $0,1 \mathrm{mg} / \mathrm{ml}$.

Solamente durante el proceso de purificación de la miotoxina, el contenido proteico fue estimado midiendo la absorbancia de luz ultravioleta a $280 \mathrm{~nm}$ (Warburg y Christian, $1941)$.

4 Evaluación de la pureza. La pureza de la miotoxina fue determinada por electroforesis en gel de poliacrilamida (PAGE) en condiciones nativas a $\mathrm{pH}$ 7,5 y también en condiciones denaturantes con dodecil sulfato de sodio (PAGE-SDS), (Laemmii, 1970). Adicionalmente, la pureza fue evaluada por inmunodifusión e inmunoelectroforesis en geles de agarosa al 1\%. En la prueba de inmuno-electroforesis se utilizó suero antibotrópico polivalente del Instituto Nacional de Salud de Lima (Ouchterlony and Nilsson, 1978). En todos los casos las proteinas fueron teñidas con azul de coomassie.

5 Determinación del peso molecular. Se determinó por PAGE-SDS (Laemmli, 1970), empleando como proteinas estándares albúmina bovina (66 KDa), ovoalbúmina ( $45 \mathrm{KDa}$ ) y lisozima (14,3 KDa); cada proteina a una concentración de $2 \mathrm{mg} / \mathrm{ml}$. El peso molecular también fue determinado por cromatografía de filtración en gel en una columna de Sephadex G-100 (18,9 x 2 cm), equilibrada con buffer acetato de amonio 0,05 M pH 7,0, y utilizando como proteínas estándares albúmina bovina $2 \mathrm{mg} / \mathrm{ml}$ ( $66 \mathrm{KDa}$ ), anhidrasa carbónica $2 \mathrm{mg} / \mathrm{ml}$ (29 KDa) y citocromo c I $\mathrm{mg} / \mathrm{ml}$ (12,4 KDa) (Andrews, 1964).

6 Composición de aminoácidos. Para determinar la composición de aminoácidos de la miotoxina, $3 \mathrm{mg}$ de proteina se hidrolizaron al vacio a $150^{\circ} \mathrm{C}$ durante $24 \mathrm{~h}$, con $400 \mu \mathrm{l}$ de $\mathrm{HCl} 6 \mathrm{~N}$ conteniendo fenol $1 \%$ y sulfito de sodio $0,1 \%$. Luego, la muestra se dejó enfriar y secar al vacio durante $1,5 \mathrm{~h}$ y se resuspendió con $50 \mu \mathrm{l}$ de EDTA 250 partes por millón. A continuación se volvió a secar al vacío y se resuspendió en $100 \mu l$ de buffer de acoplamiento (acetonitrilo: piridina: trietilamina: agua, 10:5:2:3). Luego de secar al vacio, una vez mas, se agregó 100 ụl de buffer de acoplamiento y $5 \mathrm{ml}$ de fenilisotiocianato (PITC), y se dejó a temperatura ambiente durante 5 min. Finalmente, luego de un último secado al vacio, se resuspendió en $100, \mu l$ de buffer acetato de amonio $0,05 \mathrm{M} \mathrm{pH} 6$ (solvente $\mathrm{A}$ ). $10 \mu 1$ de esta muestra fueron utilizados para el análisis de aminoácidos por HPLC, empleando una columna de fase reversa octadecilo (C18) de $25 \mathrm{~cm}$ de largo por $4 \mathrm{~mm}$ de diametro interno. La separación se realizó a $52{ }^{\circ} \mathrm{C}$, empleando inicialmente el. solvente A, y luego acetato de amonio 0,1M pH 6 en acetonitrilo, metanol y agua (44:10:46) (solvente $B$ ), de acuerdo al siguiente protocolo de elución: 15 minutos con $100 \%$ de solvente $\mathrm{A}, 15$ minutos con $85 \%$ de solvente $\mathrm{A} y$ $15 \%$ de solvente $\mathrm{B}, 4$ minutos con $50 \%$ de solvente $A$ y $50 \%$ de solvente $B, 6$ minutos con $100 \%$ de solvente $\mathrm{B}$ y finalmente $10 \mathrm{mi}$ nutos con $100 \%$ de solvente $\mathrm{A}$.

El resultado fue comparado con el perfil obtenido con $10 \mu \mathrm{l}$ de una muestra estándar de 16 aminoácidos (25 $\mu$ mol de cada aminoácido), tratados de manera similar (Heinrikson y Meredith, 1984).

\section{Determinación de carbohidratos}

7.1 Determinación de hexosas. En el ve-neno crudo y la miotoxina aislada, se determ minó el contenido de hexosas de acuerdo al método de Winzler (1955). La mezcla de reacción contenía $0,3 \mathrm{ml}$ de agua destilada, 0,2. $\mathrm{m} /$ de la muestra alcalinizada (veneno crudo $5 \mathrm{mg} / \mathrm{ml}$ o miotoxina $1 \mathrm{mg} / \mathrm{ml}$, en $\mathrm{NaOH}$ $0, i \mathrm{~N}$ ) y $2 \mathrm{ml}$ del reactivo Orcinol $0,18 \%$ y ácido sulfúrico 19N. Esta mezela fue incubada a $80^{\circ} \mathrm{C}$ durante 15 minutos y después de enfriarla se midió la absorbancia a 540 $n$ m. Los valores obtenidos fueron convertidos a mg de hexosa por comparación a un estándar que contiene una mezcla de manosa y galactosa $0,2 \mathrm{mg} / \mathrm{ml}$, y finalmente se ex- 


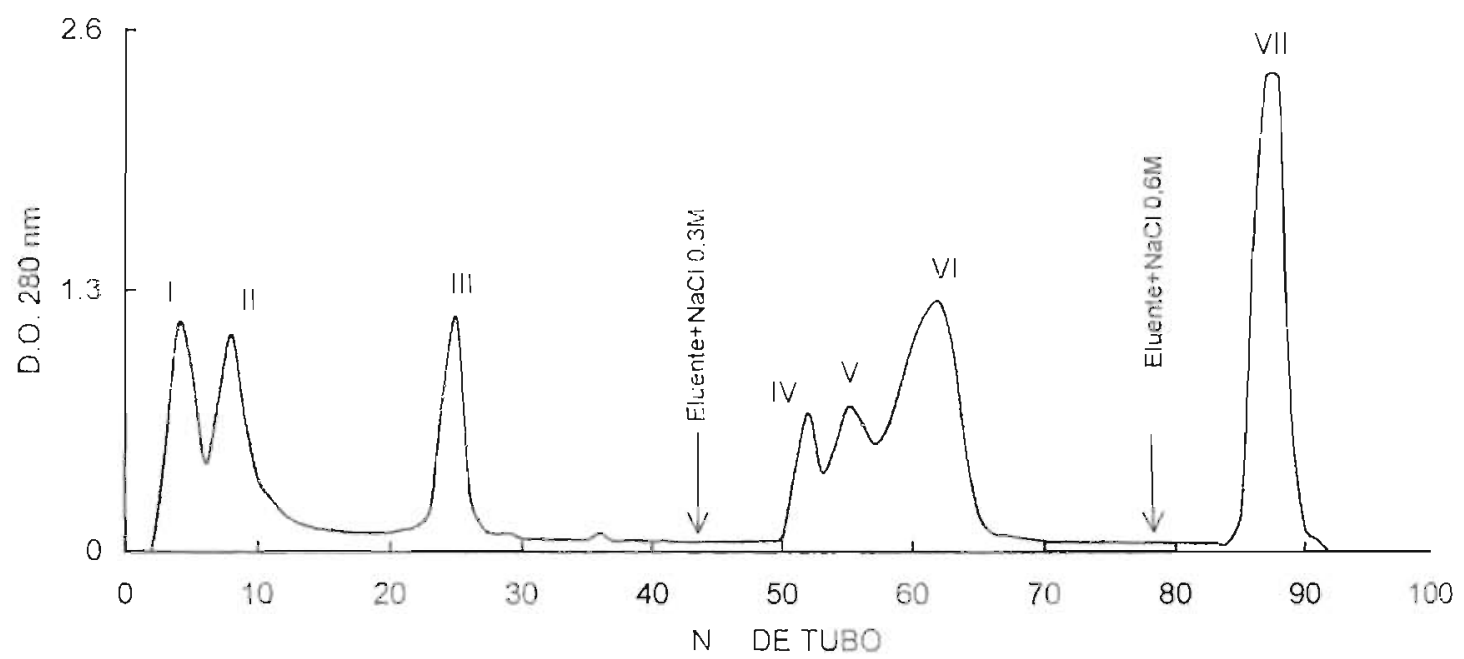

Figura 1. Purificación de la miotoxina de $B$. brazili. Al pasar el veneno de B. brazili por una columna de CM-Sephadex C-50 con buffer acetato de amonio $0,05 \mathrm{M} \mathrm{pH} \mathrm{7,} \mathrm{se} \mathrm{obtuvieron}$ inicialmente tres picos de proteina $(I, I I, I I)$. Cuando al eluente se incorporó $\mathrm{NaCl} 0,3 \mathrm{M}$, se registraron 3 picos más (IV, V, VI) y finalmente al usar $\mathrm{NaCl} 0,6 \mathrm{M}$ se obtuvo un último pico (VII) el cual mostró tener la actividad miotóxica.

presaron como porcentaje de hexosa respecto de la cantidad de proteina.

7.2 Determinación de hexosaminas. La determinación de hexosamina en el veneno cruclo y la miotoxina aislada, se realizó por el método de Winzler (1955). Inicialmente las muestras fueron sometidas a una hidrólisis ácida a $100^{\circ} \mathrm{C}$ durante 4 horas $(0,2 \mathrm{ml}$ del veneno crudo $1.0 \mathrm{mg} / \mathrm{ml}$ o MTX $2 \mathrm{mg} / \mathrm{ml}$, con $1,8 \mathrm{ml}$ de HCL $3 \mathrm{~N}$ ), y luego se agregaron 2 mi de $\mathrm{NaOH} 3 \mathrm{~N}$. De esta mezcla, se tomaron

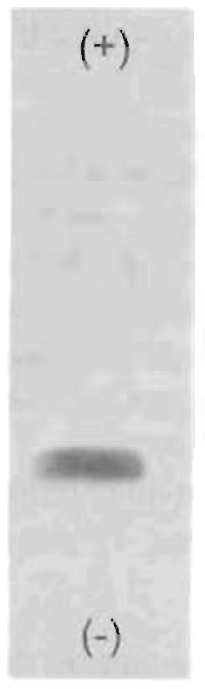

(A)

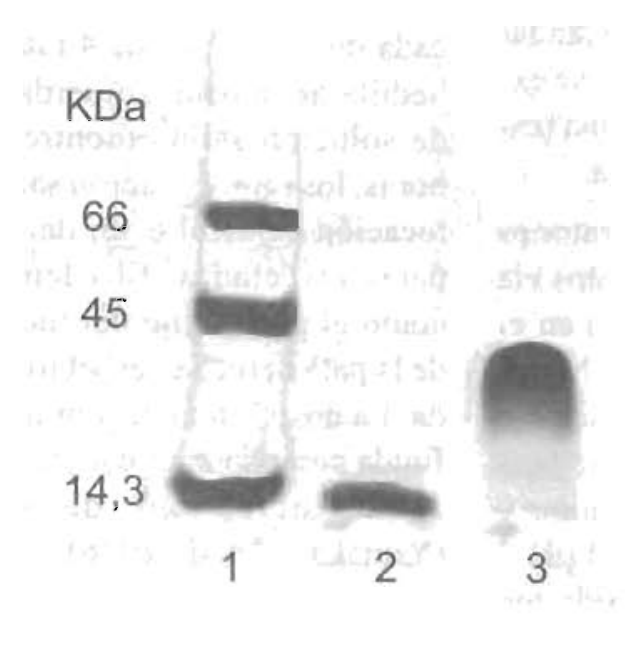

(B)
Figura 2. Electroforesis en gel de poliacrilamida. (A) Electroforesis de la miotoxina aislada, en condiciones nativas a $\mathrm{pH} 7,5$ en donde se observa una sola banda proteica con movilidad hacia el cátodo. (B) Se puede ver la PAGE-SDS de la miotoxina aislada, siendo evidente la presencia de una sola banda proteica tanto en condiciones reductoras como no reductoras, pero con diferentes movilidades electroforéticas. En el carril (1) están las proteinas estándares: albúmina (66 KDa), ovoalbumina (45 KDa) y lisozima (14,3 KDa); el carril (2) corresponde a la miotoxina reducida (15 KDa) y en el carril (3) se muestra la miotoxina no reducida (30 KDa). 


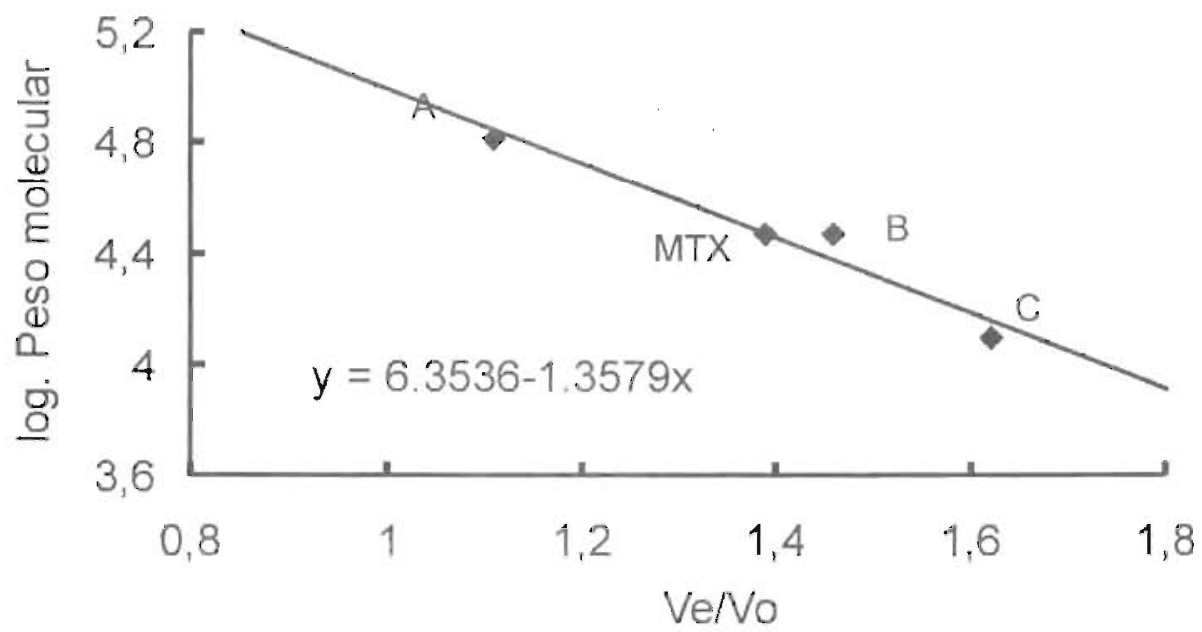

Figura 3. Cálculo del peso molecular de la miotoxina por cromatografia de filtración en Sephadex G-100. Se construyó una curva estándar de albúmina, $66 \mathrm{KDa}(\mathrm{A})$, anhidrasa carbónica, 29 $\mathrm{KDa}(\mathrm{B})$ y citocromo c, 12,4 KDa (C), ploteando el VeNo versus el log. del peso molecular de cada proteina. El Ve/Vo de la miotoxina (MTX) permitió estimar un peso molecular de $29 \mathrm{KDa}$

$0,3 \mathrm{ml}$ que se incubaron con $0,2 \mathrm{ml}$ de agua $\mathrm{y}$ $0,5 \mathrm{ml}$ de acetil acetona a $100^{\circ} \mathrm{C}$ por $15 \mathrm{mi}$ nutos. Luego, se agregó $2 \mathrm{ml}$ de etanol $95 \%$ y $0,5 \mathrm{ml}$ del reactivo de Erlich $(0,4 \mathrm{~g}$ de $\mathrm{p}$ dimetilaminobenzaldehido, $15 \mathrm{ml}$ de metanol y $15 \mathrm{ml}$ de $\mathrm{H}_{2} \mathrm{SO}_{4}$ ). Finalmente, después de 30 minutos de reposo a temperatura ambiente, se midió la absorbancia a $530 \mathrm{~nm}$ y los valores obtenidos fueron convertidos a mg de hexosamina por comparación con un estándar de glucosamina $0,5 \mathrm{mg} / \mathrm{m}$ l. Los valores se expresaron como porcentaje de hexosamina respecto de la cantidad de proteína usada.

8 Actividad miotóxica. Cuatro ratones albinos de $20 \mathrm{~g}$ de peso fueron inoculados vía i. $\mathrm{m}$. con $0, \mathrm{l} \mathrm{mi}$ de miotoxina $(60 \mu \mathrm{g})$ en el músculo gastrocnemius. Luego de 24 horas, los animales se sacrificaron por dislocación cervical, y una porción del músculo fue fijado en glutaraldehído al $3 \%$ durante 2 horas y luego tratado con buffer fosfato $0,1 \mathrm{M} \mathrm{pH} 7$ durante 3 horas. Posteriormente, el tejido fue tratado con concentraciones crecientes de alcohol etílico al $30,50,70,80,90,96$ y $100 \%$, y finalmente embebido en una resina Spurr para cortar secciones de $1 \mathrm{~mm}$ de espesor, que fueron teñidas con azul de toluidina al $0,5 \%$. Los daños morfológicos fueron observados y fotografiados a través de un microscopio de luz.

9 Actividad edemática. Fueron inyectadas diferentes cantidades de miotoxina (15, 30 y $45 \mu g$ ) disueltas en $50 \mu \mathrm{l}$ de solución salina en lia almohadilla de la pata derecha de ratones de $20 \mathrm{~g}$ de peso, empleándose para cada dosis, grupos de 4 ratones. En la almohadilla de la pata izquierda se inyectó $50 \mu$ l de solución salina (control). Después de 3 horas, los ratones fueron sacrificados por dislocación cervical a fin de cortar y pesar las patas inyectadas. El edema fue expresado como el porcentaje del incremento del peso de la pata derecha respecto de la pata izquierda. La dosis edemática mínima (DEM) es definida como la cantidad de toxina que produce un incremento de: $30 \%$ en el peso (Yamakawat et:al., 1976).

10. Actividad hemolítica. La mezcla de reacción contenia $0,8 \mathrm{ml}$ de buffer isotónico, $0,1 \mathrm{ml}$ de glóbulos rojos y $0,1 \mathrm{ml}$ de miotoxina (100 mg) en buffer acetato de amonio 0,05 M 

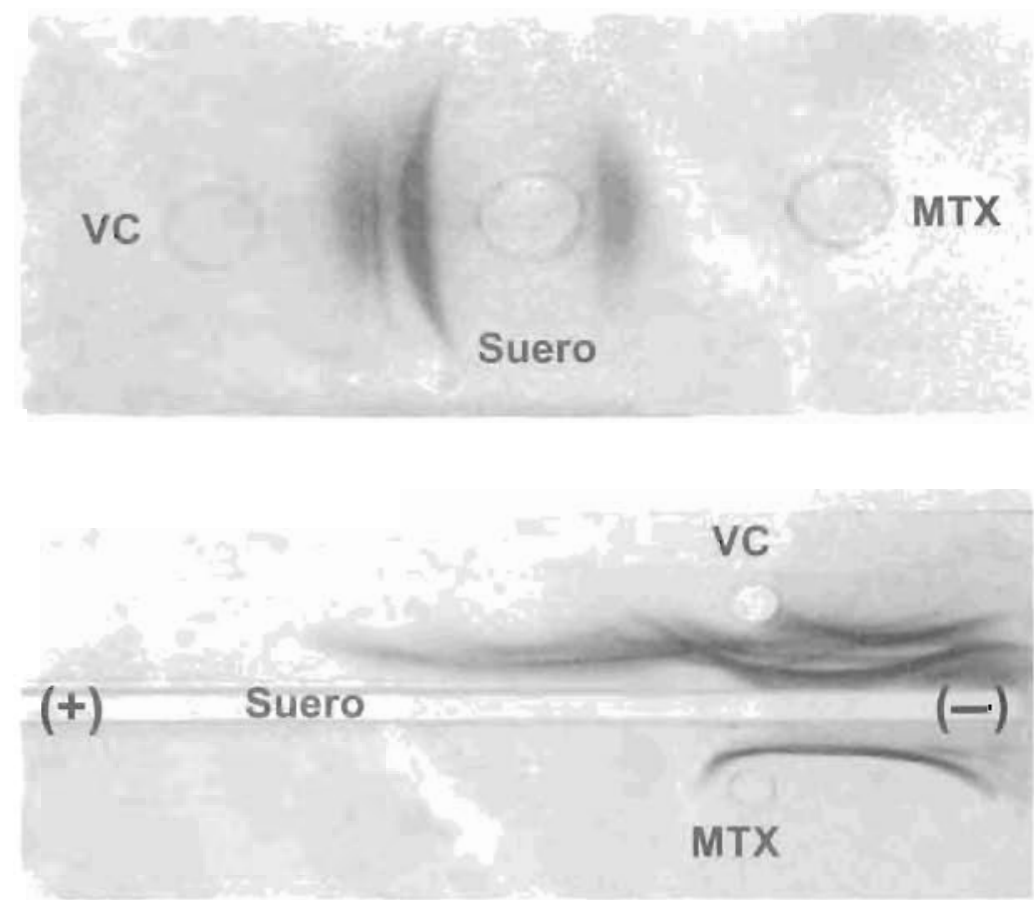

Figura 4. inmunodifusión (A) e inmunoelectroforesis (B) del veneno crudo (VC) y la miotoxina (MTX) de B. brazili. En ambos casos el veneno crudo formó varias bandas de proteina con el suero antibotrópico, mientras que la MTX originó una sola banda de proteina.

pH 7, I. Esta mezcla se incubó a $37^{\circ} \mathrm{C}$ durante $2 \mathrm{~h}$ y la reacción se detuvo con $2 \mathrm{ml} \mathrm{de}$ $\mathrm{NaCl} 0,9 \%$ frío a pH 7,3 , que contenía EDTA $200 \mathrm{mM}$, luego de lo cual se centrifugó a 200 x g por 10 minutos. La hemólisis se determinó por la liberación de hemoglobina leída a $540 \mathrm{~nm}$ y fue expresada como porcentaje total de hemoglobina contenida en $0,1 \mathrm{ml}$ de glóbulos rojos empacados y hemolizados con 2,9 $\mathrm{ml}$ de agua destilada (Condrea et al., 1964).

11 Actividad anticoagulante. Plasma humano citratado fue centrifugado a $4000 \mathrm{xg}$ durante 20 minutos, a fin de obtener plasma. pobre en plaquetas. Se incubó 200 ب̣l de este plasma a $37^{\circ} \mathrm{C}$ durante 10 minutos, con 0,1 $\mathrm{mi}$ de miotoxina (que contenía desde 2 hasta $30 \mu g$ de proteína). Enseguida se agregó 0,1 $\mathrm{mi}$ de $\mathrm{CaCl}_{2} 25 \mathrm{mM}$, y se midió inmediatamente el tiempo de coagulación. La actividad anticoagulante fue determinada midiendo el retardo en el tiempo de coagulación del plasma, con respecto a un control sin miotoxina.

\section{RESULTADOS Y DISCUSIÓN}

1. Purificación de la miotoxina. Al pasar el veneno crudo de B. brazili por la columna de CM-Sephadex C-50, se obtuvieron tres picos de proteina que eluyeron directamente, con el buffer de corrida. Posteriormente, al incorporar $\mathrm{NaCl} 0,3 \mathrm{M}$ en el buffer de elución, se obtuvieron tres picos más y finalmente empleando $\mathrm{NaCl} 0,6 \mathrm{M}$ se obtuvo un sétimo pico, el cual mostró tener actividad miotóxica (Fig. 1); es decir, en este sistema la miotoxina interactuó fuertemente con el gel y sólo fue posible separarla con $0,6 \mathrm{M}$ de $\mathrm{NaCl}$, siendo la última proteína del veneno en ser eluida. Esto nos indica que la miotoxina a $\mathrm{pH} 7,0$ adquiere una fuerte carga positiva, la cual le permite interactuar con los grupos carboximetil del gel cargados negativamente. Este hecho implica que el pl de la miotoxina es mayor que 7,0 y por lo tanto se trata de una proteina básica. 


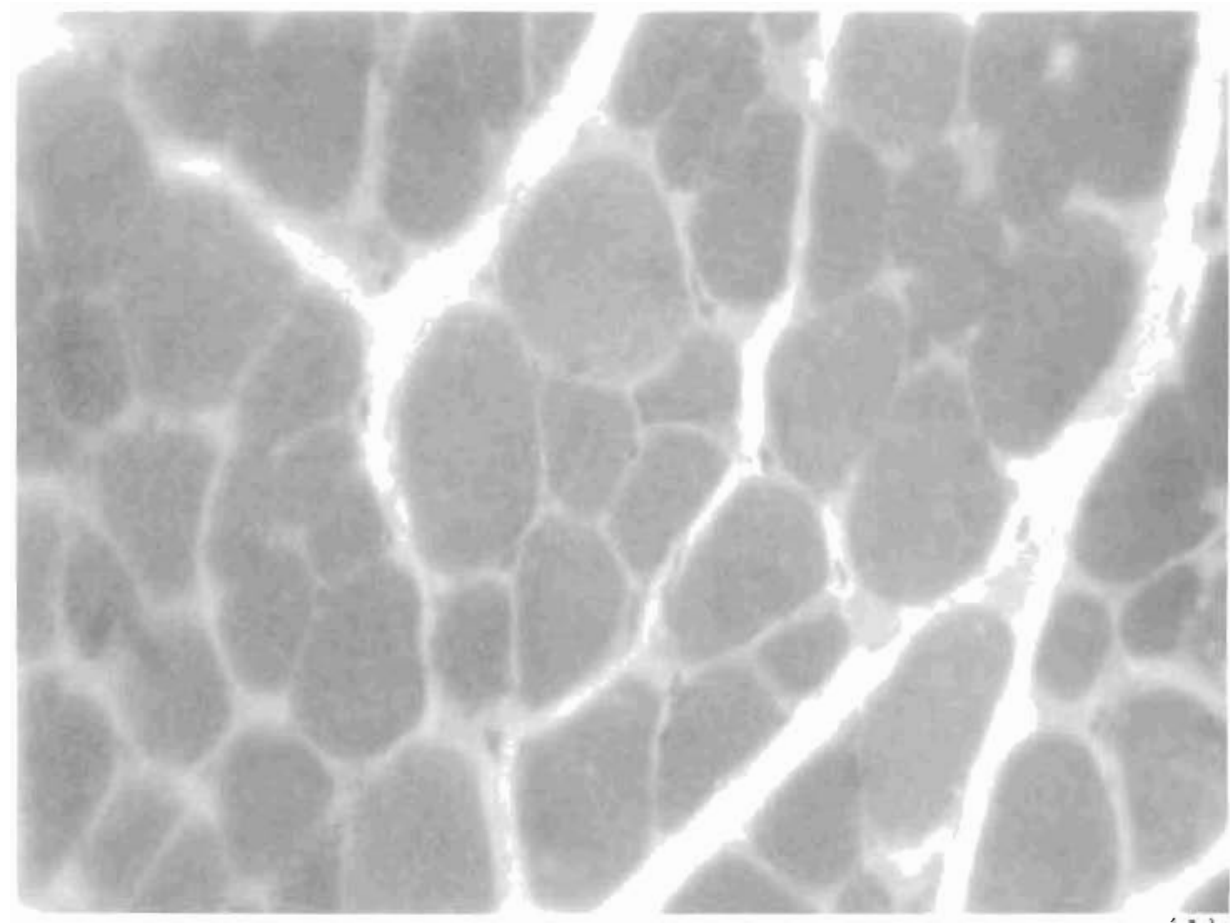

(A)

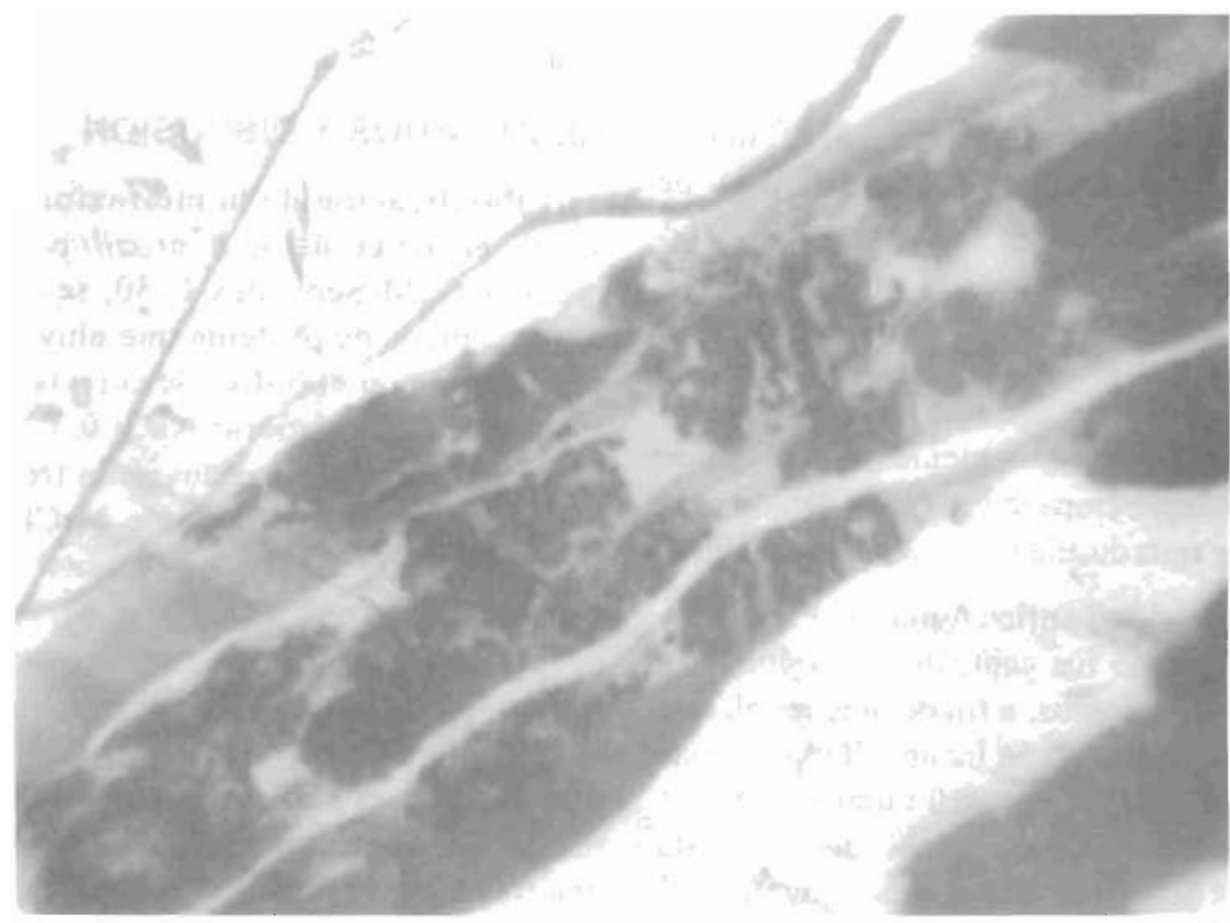

(B)

Figura 5. Actividad miotóxica. (A) Observación al microscopio de luz de un corte transversal de músculo gastrocnemius de ratones albinos no tratados con miotoxina en donde se observan intactas las fibras musculares. (B) Necrosis producida por la miotoxina. 


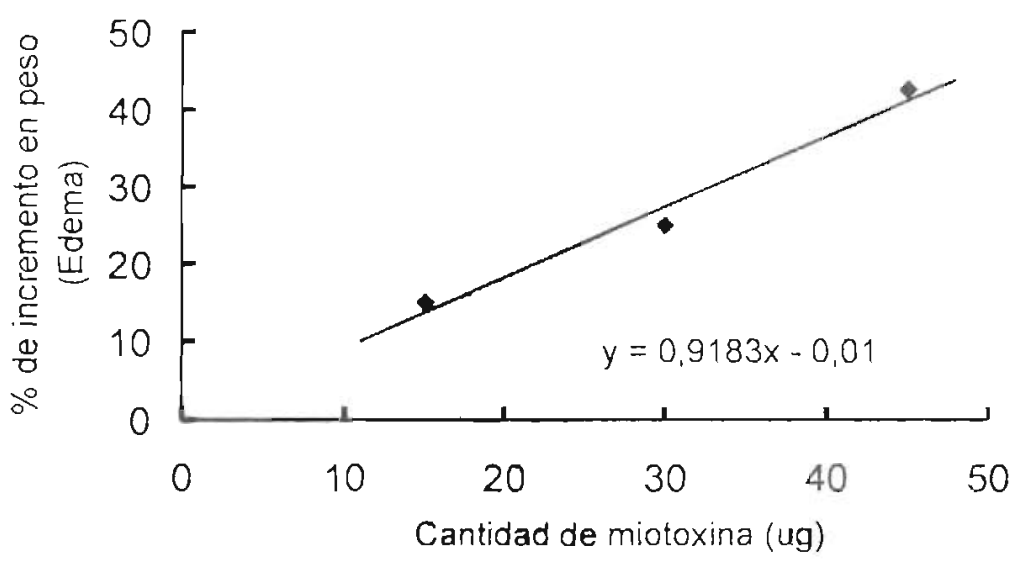

Figura 6. Dosis edemática mínima. El edema producido por la miotoxina fue dependiente de la dosis; se encontró una DEM de $32,6 \mu \mathrm{g}$.

La natura leza básica de esta proteína es una caracteristica común a todas las miotoxinas aisladas de venenos de serpientes del género Bothrops, lo cual es aprovechado para separar esta clase de proteínas mediante cromatografía du intercambio catiónico a $\mathrm{pH}$ 7,0. Asi, por ejemplo, podemos mencionar las miotoxinas aisladias de los venenos de $B$ asper y B. numnifer (Gutiérrez et al., 1984; Gutiérrez et al., 1986; Lomonte et al., 1990). Asimismo, Soares et al. (1998) emplean un solo paso cromatográfico para purificar la miotoxina de B. moojeni, y Toyama et al. (1995) hacen lo mismo con la miotoxina de B. pirajai, pero mediante HPLC.

Por el método de Lowry et al. (1951) se determinó que la mioloxina aislada representa el $25 \%$ de la proteina total del veneno, lo cual denota la importancia que debe tener como coniponente del veneno, durante cl proceso de envenenamionto y en la digestión de la presa. En el caso de las miotoxinas I y II del veneno de $B$. moojeni, ellas constituyen el $12 \%$ de la proteína total del veneno (Soares et al., 1998), mientras que la bothropstoxina de B. jararacussu representa el 15\% (HomsiBrandeburgo et al., 1988).

2 Evaluación de la pureza y peso molecular. La miotoxina aislada mostró tanto por PAGE en condiciones nativas, PAGESDS, inmunodifusión e inmunoelectroforesis, una sola banda de proteina, todo lo cual confirmó la idoneidad del método de purificación.

Particularmente la electroforesis en condiciones nativas a pH 7,5 mostró la migración catódica de la miotoxina, debido a su naturaleza básica.

Asimismo, la PAGE-SDS demostró que la proteína aislada corresponde a una única banda homogénea pero con diferentes movilidades electroforéticas, según las condiciones sean reductoras o no reductoras. El peso molecular estimado en condiciones reductoras fue de 15 $\mathrm{KDa}$, mientras que en condiciones no reductoras, el peso fue de $30 \mathrm{KDa}$ (Fig. 2); adicionalmente, la banda obtenida en condiciones no reductoras fue algo difusa. Estos resultados permiten deducir que la miotoxina aislada es una proteina constituida por dos cadenas polipeptidicas de 15 KDa cada una, y el hecho de que en condiciones no reductoras la banda proteica sea difusa indicaría que las cadenas polipeptidicas contienen varios enlaces disulfuro intracadena, lo que dificulta que las cadenas se desplieguen totalmente y queden homogéneamente cubiertas con SDS. Por otro lado, al calcular el peso molecular en condiciones nativas por cromatografia de filtración, se obtuyo un valor de $29 \mathrm{KDa}$ (Fig. 3), lo cual guarda correlación con el valor calculado por PAGE-SDS en condiciones no reductoras, confirmándose que la proteína tiene 2 cadenas polipeptídicas. 
Tabla 1. Composición de aminoácidos de la miotoxina de Bothrops brazili

\begin{tabular}{c|c}
\hline Aminoácido & $(\%)$ \\
\hline Asx (Asp+Asn) & 6,1 \\
Glx (Glu+Gln) & 4,8 \\
Ser & 8,3 \\
Gly & 13,2 \\
His & 1,7 \\
Arg & 6,6 \\
Thr & 5,1 \\
Ala & 9,2 \\
Pro & 8,5 \\
Tyr & 9,7 \\
Val & 5,5 \\
Met & 2,2 \\
Ile & 2,0 \\
Leu & 7,4 \\
Phe & 0,2 \\
Lys & 9,0 \\
& \\
\hline
\end{tabular}

Otras miotoxinas aisladas también tienen la particularidad de ser proteínas diméricas con pesos moleculares alrededor de $30 \mathrm{KDa}$; asi tenemos que la miotoxina aislada de $B$. nummifer y la miotoxina II de $B$. asper son proteinas constituidas por dos cadenas polipeptídicas de $16 \mathrm{kDa}$ cada una (Gutiérrez et al., 1986 y Lomonte y Gutiérrez, 1989). En el caso de la miotoxina aislada de $B$. insularis, ésta también es un dímero pero cada una de las cadenas tiene un peso de $15 \mathrm{KDa}$ (Selistre et al., 1990).

Sin embargo, otras miotoxinas son mononéricas, tal es el caso de las miotoxinas I y III del veneno de B. asper, las cuales son de 14 y $16 \mathrm{KDa}$, respectivamente (Gutiérrez et al., 1984; Kaiser et al., 1990) mientras que las miotoxinas I y II de B. moojeni son de 15 KDa cada una (Lomonte et al., 1990)

Las pruebas de inmunodifusión e inmunoelectroforcis mostraron que la miotoxina formó una banda homogénea de proteína al ser enfrentada con suero antibotrópico polivalente, mientras que el veneno crudo formó varias bandas o arcos de precipitación (Fiig. 4). Cabe destacar que la banda obtenida ell la inmunoelectroforesis a pH 8,3 aparece desplazada hacia el cátodo, lo cual significa que incluso a este $\mathrm{pH}$ la miotoxina está cargada positivamente, confirmándose su carácter básico.

3 Composición de aminoảcidos. Del análisis de aminoácidos, se encontró que la miotoxina conticne un mayor porcentaje de aminoácidos básicos ( $9 \%$ de Lys y $6,6 \%$ de Arg) con respecto all porcentaje de aminoácidos ácidos $(6,1 \%$ de Asp y $4,8 \%$ de Glu) (Tabla 1). Es decir, la miotoxina posee $15,6 \%$ de Lyst Arg, lo que en comparación al $10,9 \%$ de Asp+Glu, confirma su naturaleza básica. Esta diferencia entre aminoácidos básicos y ácidos debe ser incluso mayor, si se tiene en cuenta que el porcentaje de Asp+Glu incluye además el contenido de Asn y GIn, los cuales durante la hidrólisis de la proteina se convierten en $\Lambda$ sp y Glu, respectivamente. Además, debemos señalar que el porcentaje de Lys+Arg encontrado es similar a los hallados en otras miotoxinas, tal como se muestra. en la tabla 2.

A la fecha, se ha encontrado que todas las miotoxinas aisladas de venenos del género Bothrops son proteinas básicas, que estructuralmente están relacionadas a las fosfolipasas. En realidad, el análisis de la estructura primaria de estas miotoxinas ha mostrado que este grupo puede subdividirse en dos subclases: las fosfolipasas D-49, las cuales poseen un resto de ácido aspártico en la posición 49 y tienen actividad de fosfolipasa, y las fosfolipasas $K-49$, las cuales tienen un residuo de lisina en la posición 49 y carecen de actividad enzimática (Ownby et al., 1999). La presencia de ácido aspártico en la posición 49 


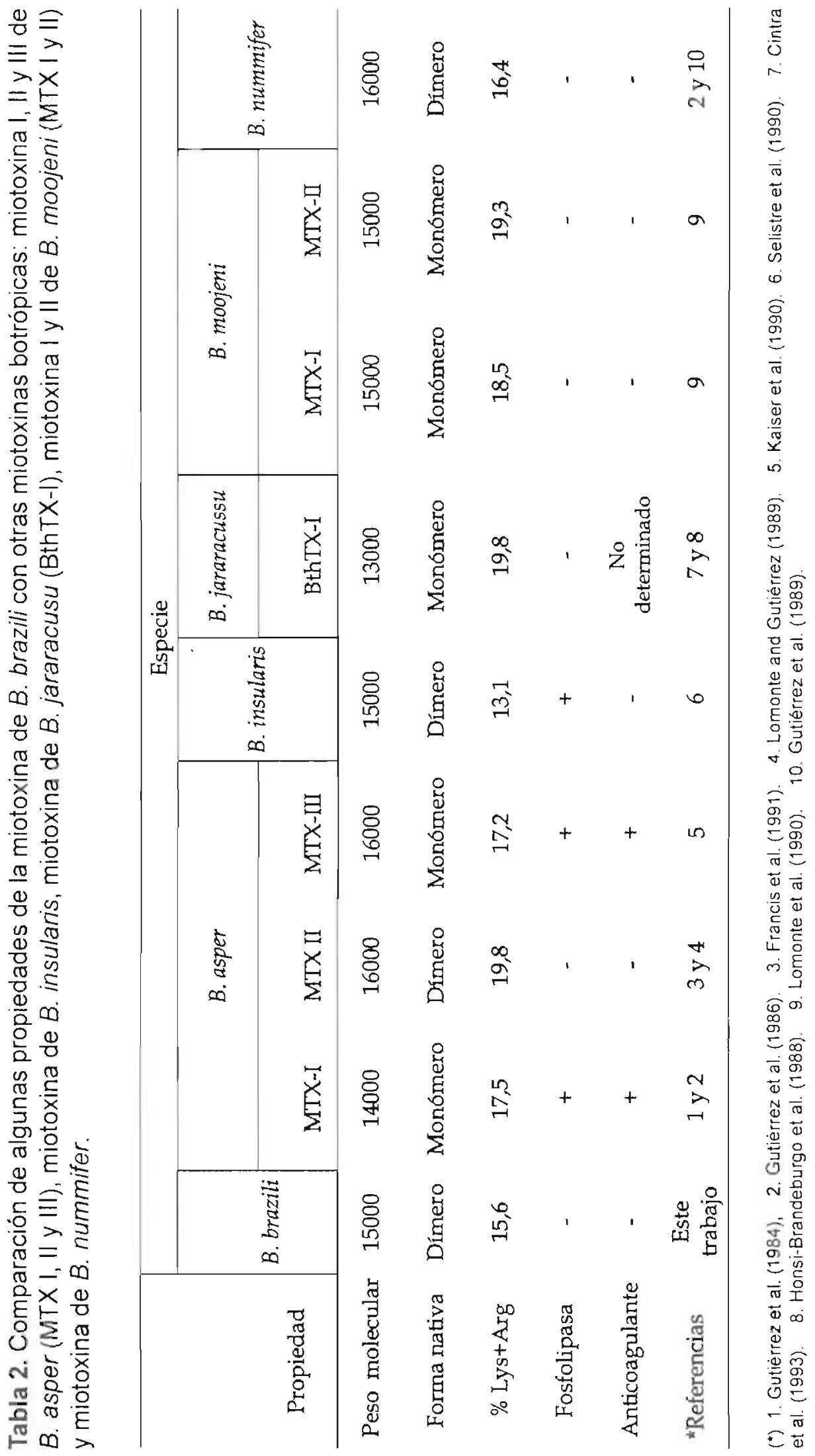


es crucial para fijar $\mathrm{Ca}^{++}$, el cual es esencial para la actividad catalítica; por ello las fosfolipasa: K-49 carecen de actividad enzimática. Algunos estudios evolutivos sugieren que las fosfolipasas K-49 surgieron de la duplicación de un gen ancestral de fosfolipasa, lo cual es sumamente intrigante, ya que aparentemente la evolución preservó una mulación crucial para la actividad catalítica en las fosfolipasas D-49.

4 Determinación del contenido de carbohidratos. Los análisis de hexosas y de hexosaminas de acuerdo al método de Winzler (1955) dieron resultados negativos con la miotoxina. Sin embargo, en el veneno crudo se halló $0.65 \%$ de hexosa y $1,33 \%$ de hexosamina. Esto demuestra que la miotoxina aislada no es una glicoproteína, lo que es coincidente con lo descrito en una amplia variedad de miotoxinas botrópicas. No obstante, los valores de $0,65 \%$ de hexosa y $1,33 \%$ de hexosamina, encontrados en el veneno crudo, serian producto de azicares ligados a otras proteínas del veneno y azúcares libres.

5 Actividad miotóxica. El análisis histológico del músculo gastrocnemius de raión tratado con miotoxina evidenció una severa necrosis del tejido, observándose no sólo una desorganización de las fibras musculares, sino además una gran infiltración de glóbulos blancos en el tejido (Fig. 5). Considerando que esta proteina carece de actividad de fosfolipasa, nuestros resultados corroboran lo señalado por algunos autores en el sentido de que la acción miotóxica no depende de la hidrólisis de fosfolípidos (Gutiérrez, 1984; Homsi-Brandeburgo et al., 1988; Gutiérrez et al., 1989). Asimismo se trataría de una miotoxina del grupo de las fosfolipasas K-49.

Sin embargo, un aspecto particularmente importante y que está en pleno estudio, es la manera como esta proteina ejercería su acción destructiva sobre el tejido muscular, toda vez que es una proteina sin actividad enzimática.

6 Actividad edemática. La miotoxina de B. brazili fue capaz de inducir edema en la almohadilla plantar de ratones albinos. Los incrementos en peso obtenidos con 15,30 y 45 $m g$, fueron de $15,1,24,8$ y $42,6 \%$ respectivamente, detcrminándose una DEM de $32,6 \mu \mathrm{g}$ de proteina (Fig. 6).

La actividad formadora de edema se define como el incremento en la permeabilidad microvascular que conduce a una extravasación de fluido y su acumulación ell los espacios intersticiales de los tejidos. Sin embargo, muy pocos estudios se han realizado para determinar la naturaleza exacta del mecanismo del ederna causado por miotoxinas, aunçue en algunos casos se ha determinado la DEM. Así, por ejemplo, Lomonte y Gutiérrez (1989) han reportado que la miotoxina II de B. asper, tiene una DEM de $38 \mathrm{mg}$, la cual es similar a la encontrada en este trabajo para la miotoxina de $B$. brazili (32,6 $\mathrm{mg}$ ). Un aspecto reconocido en la inflamación es la participación de fosfolipasas $A_{2}$, las cuales incluso han sido aisladas de fluidos inflamatorios. Esta acción edemática de las fosfolipasas fue correlacionada con su capacidad para hidrolizar fosfolípidos (Lloret and Moreno, 1993). Sin embargo, la miotoxina de B. brazili, al igual que otras miotoxinas botrópicas, no tiene actividad enzimática, 10 cual sugiere que su efecto edemático tampoco depende de la hidrólisis directa de fosfolípidos y que algún mecanismo alternativo estaría involucrado, por ejemplo, la acción directa de la miotoxina sobre células endoteliales.

7 Actividad hemolítica y anticoagulante. La miotoxina aislada no mostró tener actividad hemolítica directa sobre glóbulos rojos humanos, ni fue capaz de retardar el tiempo de coagulación del plasma humano recalcificado, lo cual guarda relación y es coherente con el hecho de que esta miotoxina carece de actividad de fosfolipasa. En particular. todas las miotoxinas que ejercen un retardo en la coagulación del plasma citratado y recalcificado muestran tener actividad de fosfolipasa, $y$ se supone que es la capacidad 
de hidrolizar ciertos fosfolipidos, que participan en el proceso de coagulación sanguínea, lo que les confiere un efecto anticoagulante; tal es el caso de las miotoxinas aisladas de $B$. atrox y de B. asper (MTX I y III), todas las cuales tienen actividad de fosfolipasa y son a la vez anticoagulantes. En cambio la miotoxina estudiada en este trabajo es similar a las miotoxinas de $B$. nummifer, $B$. asper (MTX II) y $B$. moojeni (MTX II), en el sentido de que todas carecen de actividad de fosfolipasa y también de actividad anticoagulante (Prado-Franceschi et al., 1998).

\section{Agradecimientos}

Esta investigación contó con el apoyo económico del CSI (Proyecto 001001141). Los autores agradecen de manera especial a los Biólogos Elizabeth Neyra y Miguel Neira por su valioso apoyo en el procesamiento histológico y determinación del contenido de aminoácidos, respectivamente.

\section{REFERENCIAS BIBLIOGRÁFICAS}

Andrews, P. 1964. T'he gel filtration behavior of proteins to their molecular weights over a wide range. Biochemical Journal 96:595-606.

Azañero, M.; E. Escobar y A. Yarlequé, A. 2000. Purificación de una enzima proteolítica del veneno de Bothrops brazili y estudio de su actividad sobre fibrinógeno. Rev. Peru. Biol. 7(1): 55-66.

Carrillo, N. 1983. Contribución al conocimiento de las serpientes venenosas del Perú de las familias Viperidae, Elapidae e Hydrophidae. Publ. Mus. Hist. Nat. UNMSM. Serie A, N. 30, 55 PP.

Carrillo, N. y J. Icochea. 1995. Lista taxonónica preliminar de los reptiles vivientes del Perú. Folleto de divulgación: Publ. Mus. Hist. Nat. UNMSM. $49: 1-27$.

Cintra, A.; S. Marangoni; B. Oliveira and J. Giglio. (1993). Bothropstoxin-I: amino acid sequence and function. J. Protein Chem. 12, 57-64.

Condrea, E.; A. De: Vries and J. Mager. 1964. Hemolysis and splitting of human erytrocyte phospholipids by snake venoms. Biochem. Biophys. Acta 84: 60.

Francis, B.; J. Gutiértez; B. Lomonte and 1. Kaiser. (1991). Myotoxin Il from Bothrops asper (terciopelo) venom is a lisien-49 phospholipase $A_{2}$. Arch Biochem. Biophys. 284: 352-359.
Gutiérrez, J. I. Chaves; J. Gent: B. Lomonte; Z Camacho and K. Schosinsky. (1989). Myonecrosis induced by a basic myoloxin isolated from the venom of the snake Bothrops nummifer (jumping vipur) from Costa Rica. Toxicon $27.735-745$.

Gutiérrez. J. and B. Lononte. 1997. Phospholipase $A_{2}$ Myotoxins lrom Bothrops snake venoms. In: Venum Phospholipase A, Enzymes: Structure, Function, and Mechanism. (Ed. R. Manjunatha Kini). John Wiley and Sons. 321 352.

Gutiérrez, J.; B. Lomonte and L. Cerdas. 1986. Isolation and partial chanacterization of a myotoxin trom the venom of the snake Bothrops nummifer. Toxicon 24(9): 885-894.

Gutiérrez, J.; C. Ownby and G. Odell. 1984. Isolation of a Myotoxin from Bothrops asper venom: Partial Characterization and action on skelctal muscle. Toxicon, 22(1): 115-128

Heinrikson, R. and S. Meredith. 1984. Aminoacid analysis by reverse-phase high-performance liquid chromalography: precolumn derivatization with phenylisothiocyanate. Analitical Biochemistry 136: 65-74.

Homsi-brandeburgo, M.; L. Queiroz; H. Santo-Neto; L. Rodrigues-Simioni and J. Giglio. 1988. Fractionation of Bothrops jararacussu whake venom: Partial chemical characterization and biological activity of bothropstoxin. Toxicon 26: $615-627$

Kaiser, I; J. Gutiérrez; D. Plummer; S. Aird and G Odell. 1990. The amino acid sequence of a myotoxic phospholipase from the venom of Bothrops asper: Arch. Biochem. Biophys. 278: 319-325.

Kini, R. and S. Iwanaga. 1986a. Structure-function relationships of phospholipases. I: prediction of presynaptic neurotoxicity. Toxicon 24: 527 541.

Kini, R. and S. Iwanaga. 1986b. Structure-function relationships of phospholipases. II: charge density distribution and the myotoxicity of presynaptically neurotoxic phospholipases. Toxicon 24: 895.905 .

Laemmli, U. 3970 . Cleavage of structural proteins during the assembly of the head of bacteriophage $\mathrm{T} 4$. Nature 22:7:680-685.

liman, J. 1996. Purificación y caracterización parcial de la enzima similar a trombina del veneno de Bothrops brazili ("jergón shushupe"). Tesis para optar el Título Profesional de Biólogo. UNMSM. 3 l'. pp.

Lomonte, B. and J. Gutiérrez. 1989. A new muscie daniaging toxin, myotoxin $\left[I_{n}\right.$ from the venom of the snake Bothrops asper (terciopelo). Toxicon 27: 72.5-733. 
Lomonte, B.: J. Gutićruz; M. Furtado; R. Otcro; J.-P. Rosso; O. Vargas; E Carmona and M. Rovira. 1990. Isolation of basic myotoxins from Bothrops moojeni and Bothrops atrox snake venom... Toxicon 28(10): 137-1|46.

Lowry, O.: N. Rosebrough; A. Farr and R. Randall. 1951. Protein measurement with the Folin phenol reagent. J. Biol. Chem. 193: 265-275.

Llorel, S. and J. Moreno. 1993. Fdema formation and degranulation of mast cells by phospholipase $A_{2}$ purified from porcine pancreas and snake venoni.. Toxicon 3 I (8): 949-956.

Ouchteriony, $O$ and $L_{\text {. }}$ Nilsson. 1978. Immunodiffusion and immunoelectrophoresis. In: Handbook of Experimental Inmunolog: Vol. 1 , Immunochemistry. p. 19 (Weir, D.M., De). Oxford: [3lackwcll Scientific Publications.

Onnlyy C: H. Selistre De Araujo; S. White and J. Fletcher. 1949. Lysine 49 phospholipase $A_{2}$ prolsise. Toxicon 37: 411-445.

l’antiguso, C ; E. Excobar; O. Málaga y A. Yarlequé. 1996. Aislamicnto y algunas propiedades de la Atroxina, una proteinasa del veneno de la serpiente peruana Bothrops atrox "jergon". Acta Cientílica Venezolana. 47: 67-73.

Prado-Franceschi, J.: S. Hyslop; J. Cogo; A. Andrade; M. Assakura; A. Richl; M. Cruz-Höfling and L.Rodrigues--Simioni. 1998. Characterization of a myotoxin from the Ouvenoy's gland secretion of the xenodontine colubrid Philodryis olfersii (green snake): Effects on striated muscle and the neuromuscular junction. Toxicon 36(10): 1407-1421.

Selistre, H.; L. Queiroz; O. Cuña; G. De Sousa and J. Giglio. 1990. Isolation and characterization of hemorhacic myonecrotic and edema inducing coxins from Bothrops insularis (jararaca ilhoa) snake venom. Toxicon 28: $261-273$.
Soares, A ; B. Rodrigıes: $M$. Homsi-Brandeburgo: $M$. Toyama; F. lombardi: R. Arni and J. Giglio. 1998. A rapid procedure for the isolation of the Lys-49 myotuxin II from Bothrops moojeni (caissaca) venum: Biochemical characterization, crystallization, myotoxic and edematogenic activity. Toxicon 36, (3) : 503-514.

Toyama, M.; L. Mancuso; J. Giglio; J. Novello: B. Olivira and $\mathbf{S}$. Marangoni. 1995. A quick procedure for the isolation of dimeric piratoxins I and II, two myotoxins from Bothrops pirajai snake venom. N-terminal sequencing. Biochem. Mol. Biol. Int. 37: 1047-1055

Warburg, O. And Christian. 1941. 1solierung und Kristallisation der Garungs ferments enolase. Biochem. Z. 310: 384-421.

Winzler, R. 1955. Determinations of serum glycoproteins. In: Muthuds of Bioclicnical Analysis. Lundbard, R., Fenton. J. and Mann, K. (eds). pp. 279-311.

Yamakawa, M.; M. Nosaki and Z. Hokama. 1976 Fractionation of sakishima-habu (Trimererusus elegans) venom, and Jetal, hemomhagic and edemaforming activitics of the fractions. In: Animal, Plant, and Microbial toxins, Vol. 1. Biochemistry, eds., A.. Ohsaka, K. Hayashi and Y. Sawai. Plenum Press, New York.

Yarlequé, A.; S. Campos; E. Escobar: F. Lazo; N. Sánchez: S. Hyslop; N. Marsh: P. Butterworth and R. Price. 1989. Isolation and characterization of a fibrinogen cloting enzyme from the snake Lachesis mula mua (peruvian bushmaster). Toxicon 27(11): 1189-1197.

Zeballos, J.; E. Escobar y A. Yarlequé. 1999. Aishamiento y algunas propiedades de una fosfolipasa del veneno de la serpiente Buthrops brazili. Buletín de la Sociedad Química del Perú. Vol. l.XV (1): 10-20. 